\title{
Blister-Like Supraclinoid Internal Carotid Artery Pseudoaneurysm in a 15-Year-Old Male: Case Report and Review of the Literature
}

\author{
Faizal Aminmohamed Haji Melfort R. Boulton Sandrine de Ribaupierre \\ Division of Neurosurgery, Department of Clinical Neurological Sciences, London Health Sciences Centre, \\ London, Ont., Canada
}

\section{Key Words}

Pseudoaneurysm • Blood-blister aneurysm • Trauma •

Supraclinoid internal carotid artery $\cdot$ Endovascular treatment

\begin{abstract}
With an incidence of less than 1-3 per million, pediatric aneurysms are rare clinical entities. A traumatic etiology is implicated in a large proportion of these cases, leading to the formation of both 'false' and 'true' aneurysms. These occur most often in the distal circulation, but have also been described in the supraclinoid distal internal carotid artery (ICA). Blood blister aneurysms are also found in this location; however, they have not been described in the pediatric population. We report the case of a 15 -year-old male who presented following cranial trauma with diffuse basal subarachnoid hemorrhage and limited additional intracranial pathology. Computed tomography angiography demonstrated a small, 2-mm blister-like aneurysm arising from the dorsal surface of the left supraclinoid ICA at a non-branching site. Despite early endovascular treatment with Guglielmi detachable coils, the lesion continued to grow over subsequent studies, necessitating open surgical clipping. At the time of surgery, gross pathology of the native ICA was observed, raising the
\end{abstract}

possibility of a preexisting blood-blister aneurysm. We review the epidemiology, pathophysiology and diagnostic considerations of these lesions. The endovascular and surgical management of these complex non-branching supraclinoid ICA aneurysms is also discussed.

Copyright $\odot 2012$ S. Karger AG, Basel

\section{Introduction}

Pediatric aneurysms are rare, representing $<5 \%$ of all aneurysmal subarachnoid hemorrhage (SAH) [1]. They exhibit many differences from their adult counterparts, with a predilection for males, higher rates of rebleeding (upwards of 52\% compared with $29 \%$ in adults), a greater tendency toward giant and posterior circulation lesions, a bimodal distribution in infancy and the teenage years and a higher frequency of traumatic and infectious etiologies [2-4]. As a result, these lesions are challenging to treat even in the most experienced hands [1]. We report the case of a 15-year-old male with SAH from a ruptured

Portions of this work were presented in an abstract/poster form as proceedings at the 46th Annual Canadian Neurological Sciences Federation Congress, June 15th, 2011.

\section{KARGER \\ Fax +41613061234 E-Mail karger@karger.ch} www.karger.com
(C) 2012 S. Karger AG, Basel $1016-2291 / 11 / 0476-0449 \$ 38.00 / 0$

Accessible online at: www.karger.com/pne
Faizal Haji

43 Corvette Court

Brampton, ON L7A 2H8 (Canada)

Tel. +1 6479728086

E-Mailfhaji@uwo.ca 

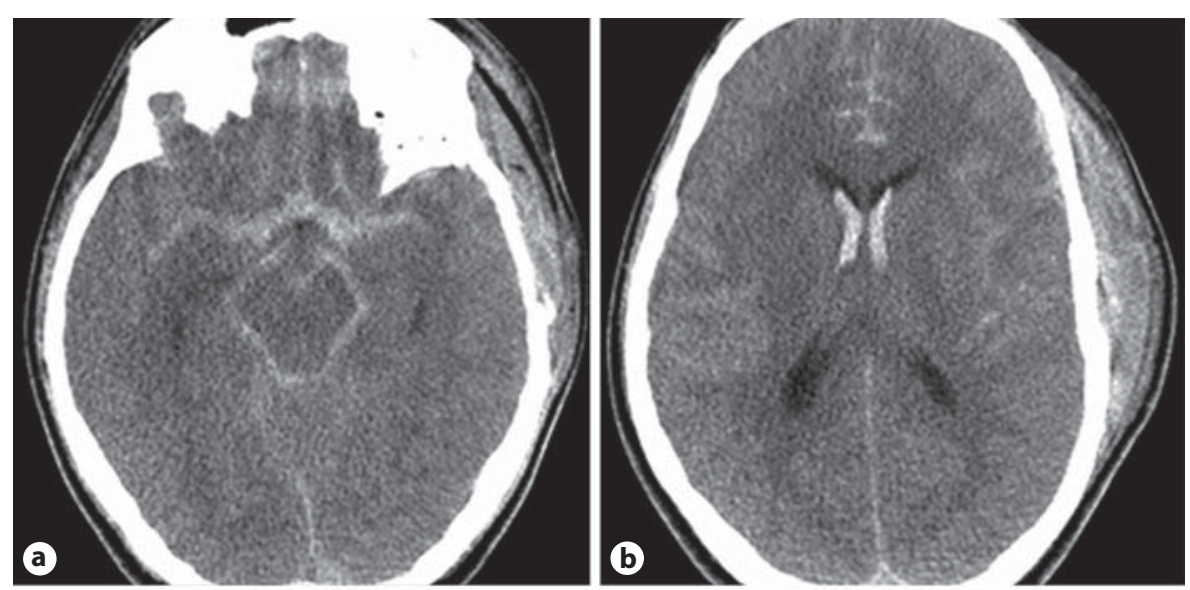

Fig. 1. Non-contrast CT of the head and CTA showing diffuse subarachnoid hemorrhage (a, b) secondary to a small, 2-mm aneurysm arising from the dorsal aspect of the supraclinoid ICA $(\mathbf{c}, \mathbf{d})$. The aneurysm has a characteristic dome-like shape commonly seen with blister-like aneurysms and arises from a non-branching site on the dorsal aspect of the supraclinoid ICA $(\mathbf{e}, \mathbf{f})$.
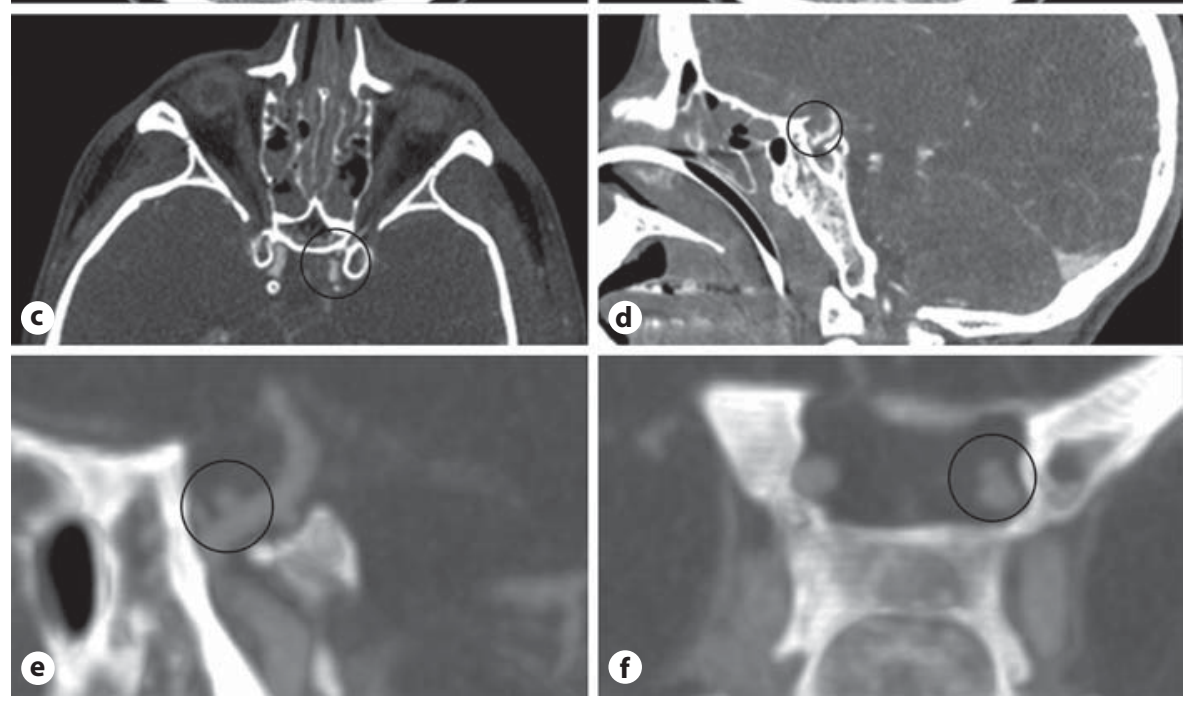

left dorsal supraclinoid internal carotid artery (ICA) aneurysm following cranial trauma. Although occurring after trauma, the location, gross appearance and behavior of this lesion more closely resembled that of a blood-blister aneurysm (BBA). These lesions have been described on the dorsal surface of the ICA in adults; however, to our knowledge they have not been reported in the pediatric population.

\section{Case Report}

A previously healthy 15 -year-old-male was found unconscious at the base of a ravine, where he was playing with friends at hide and seek. He was therefore unwitnessed when the event happened; however, he had no signs indicating a severe fall (no bruises or contusions on his face or body, other than left sided subgaleal swelling). On arrival at the pediatric trauma centre, his Glasgow Coma Scale score was 6. After initial assessment and intubation, the patient underwent an urgent computed tomography
(CT) scan of the head revealing extensive basal SAH out of keeping with his injuries. CT angiography (CTA) revealed a small, wide neck aneurysm arising from the dorsal aspect of the supraclinoid ICA at a non-branching site (fig. 1).

After ensuring clinical stability, the patient underwent cerebral digital subtraction angiography (DSA), at which time an increase in the size of aneurysm was appreciated. The initial radiological impression was that the CTA had underestimated the size of the lesion. Given its morphology and location, it was felt that endovascular coiling could be successful, and was attempted within 10 days of ictus. Although initial post-coiling angiography demonstrated no further filling of the aneurysm sac (fig. 1), interval growth of the aneurysm during the procedure was appreciated. Due to its location at a non-branching site, initial morphological appearance and aggressive growth pattern over a short interval, our impression was revised and the possibility that this lesion represented a BBA rather than traumatic pseudoaneurysm was raised.

Follow-up magnetic resonance imaging and angiography (MRI/MRA) one month after intervention demonstrated interval growth of the aneurysm with medial displacement of the coil mass (fig. 2). After confirmation of recanalization with DSA, a second attempt at coiling was made. Again, an apparently satis- 

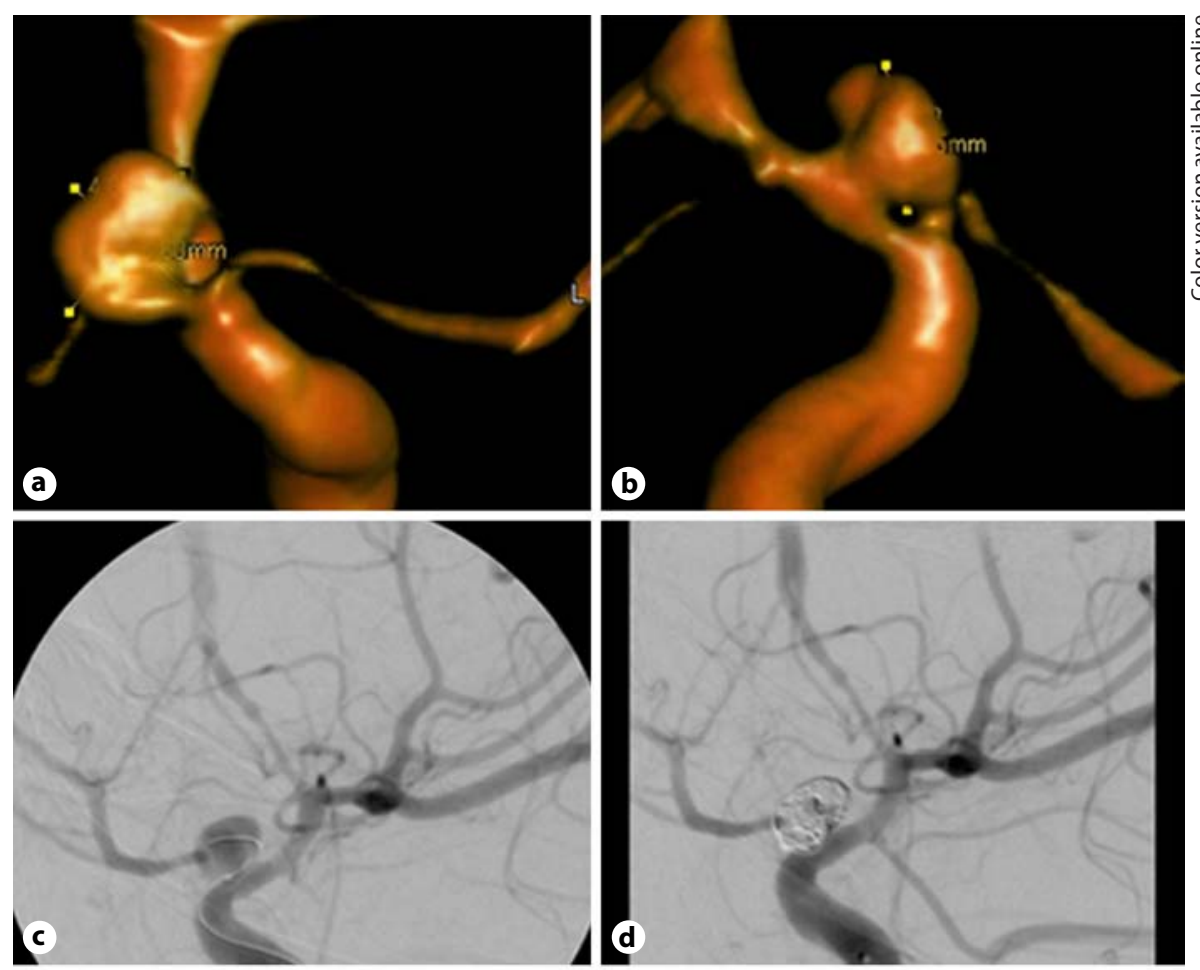

Fig. 2. Cerebral angiogram with $3-\mathrm{D}$ reconstructions $(\mathbf{a}-\mathbf{c})$ showing the enlarged aneurysm sac. $\mathbf{d}$ Despite suspected growth of the aneurysm during the interventional procedure, successful coiling was achieved using three detachable coils. Follow-up MRA (e) and cerebral angiogram (f) demonstrated regrowth of the aneurysm at the neck, with coil impaction at the dome.
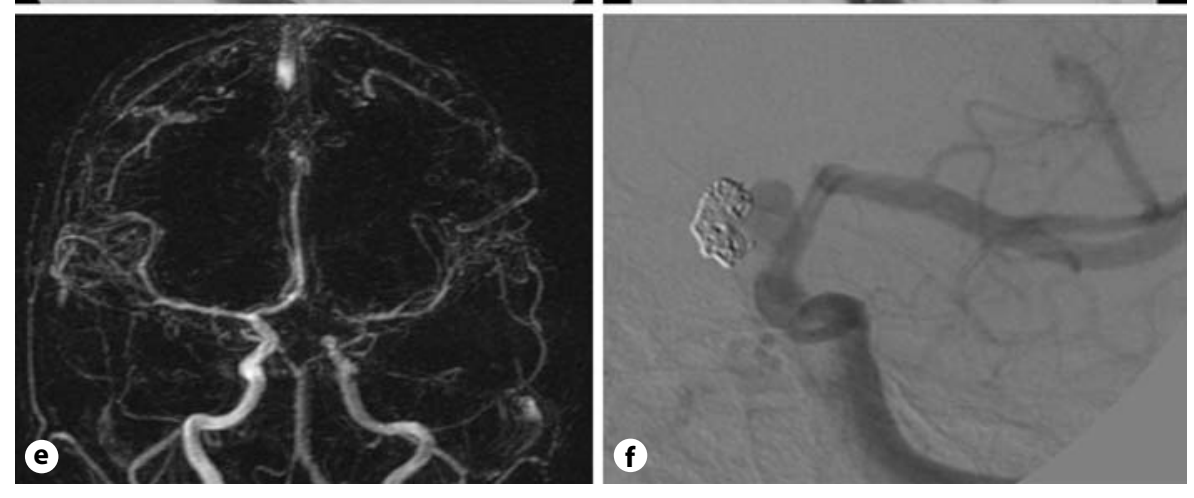

factory coiling was achieved, although with some neck remnant evident at the end of the procedure. A follow-up MRA at 5 days demonstrated further growth, after which a decision was made to treat the lesion operatively.

After successful balloon test occlusion of the left ICA, the patient was brought to the operating room for clipping of the aneurysm. Intraoperatively, the lesion and the adjacent proximal segment of the ICA were noted to have a diseased, friable adventitial surface and an appearance consistent with previously reported cases of blister-like aneurysms. An attempt to clip the aneurysm primarily resulted in a side-wall rupture of the ICA, necessitating trapping of the lesion. Intraoperative angiography demonstrated no further filling of the aneurysm and collateral flow through the anterior and posterior communicating arteries to supply the left anterior circulation (fig. 3).

MRI immediately postoperatively demonstrated a small infarct involving the left frontal lobe, caudate and posterior limb of the internal capsule. This was associated with a new-onset aphasia and facial droop, which resolved within $72 \mathrm{~h}$ of onset. At one-year follow-up, the patient has returned to school and is performing at his scholastic and social baseline, with no focal deficits. Follow-up MRA demonstrates improved blood flow in the distal left ICA, through posterior communicating collateral supply (fig. 3).

\section{Discussion}

Pediatric aneurysms are rare, representing $0.5-4.6 \%$ of surgically treated cases [5]. Compared with adult lesions, they demonstrate a predilection for uncommon anatomic locations (ICA bifurcation, posterior circulation, etc.), complex morphology and a fourfold likelihood 

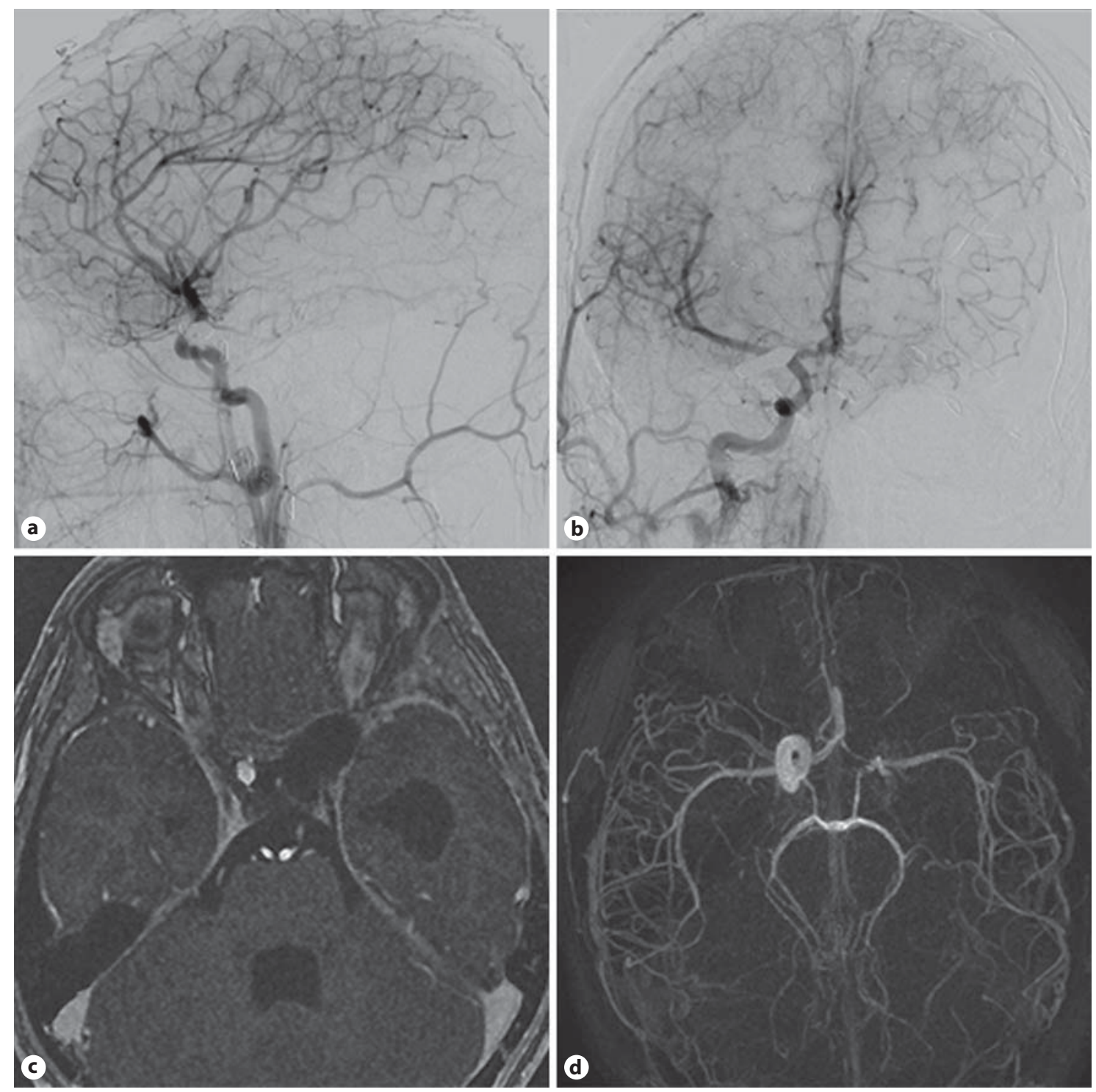

Fig. 3. Lateral (a) and AP (b) intraoperative angiogram images demonstrating no further filling of the aneurysm following aneurysm trapping. The left anterior circulation is being supplied by collateral flow through the anterior and posterior communicating arteries. Follow-up MRA showed ongoing obliteration of the left supraclinoid aneurysm (c), with recanalization of the ICA (d) as a result of collateral flow.

of symptomatic hemorrhage $[2,6]$. The proportion of traumatic and infective aneurysms is also much higher in this cohort, with posttraumatic etiologies accounting for $14-39 \%$ of all pediatric lesions [6-8].

Traumatic aneurysms of the supraclinoid ICA are exceedingly rare, with only 39 reported cases in the literature $[9,10]$. Of these, only two clearly reported involvement the dorsal surface of the supraclinoid ICA; both in adults [11]. The proposed pathophysiology of these le- sions is direct vessel injury from basal skull fracture, tearing or contusion of the vessel on the anterior clinoid, or overstretching of this segment relative to the tethered cavernous portion during impact. This results in dissection (between intima and media), partial disruption (involving intima and/or media) or complete disruption of the dorsal ICA and subsequent dissecting, true or false aneurysm formation remote from a branching site with irregular borders and a propensity to increase in size. 
Catastrophic rupture is observed in $31 \%$ of cases, with mortality of up to $50 \%[8,11-13]$. Most traumatic aneurysms present in a delayed fashion, ranging from hours to years after the inciting trauma. Rupture is the most common early presentation, bi-modally distributed at $24 \mathrm{~h}$ and 3 weeks after trauma. Delayed presentations are more often associated with mass effect after aneurysmal growth [11, 14].

Our case differs from previously reported traumatic aneurysms in this region in a number of ways. First, the concomitant presentation of trauma and SAH is uncommon. The paucity of historical information makes it impossible to determine if the SAH preceded the fall or resulted from it; however, we had no indications of a violent fall either on the CT head (which failed to demonstrate cerebral contusions), or on the face and body (aside from mild subgaleal swelling on the left side). Second, the initial blister-like appearance of the lesion, without dissection of the ICA, is also an uncommon morphological trait. Third, the sustained growth without associated rebleeding and initially successful coiling suggest that while this was clearly not a stable aneurysm, its behavior was also inconsistent with a false aneurysm or pseudoaneurysm. As such, we are left to consider an alternate explanation - that this lesion may represent a BBA. While no histological confirmation is possible, the intraoperative visualization of a friable and diseased adventitia, both on the lesion as well as proximally on the ICA, supports this theory.

BBAs represent $0.9-6.6 \%$ of ICA aneurysms in currently reported series $[15,16]$. They often present as small, hemispherical bulges at non-branching sites of the supraclinoid ICA, although other locations have been reported. Histologically, a focal defect of the intima and internal elastic lamina is typically observed, with a thin fibrous adventitial layer lacking typical collagen resulting in marked weakness of the aneurysm wall $[17,18]$. These lesions often demonstrate rapid change in both size and morphology, occasionally with progression from a blister to saccular shape, as in our case [19]. The underlying pathogenesis of these lesions is contentious, although atherosclerotic or hypertensive focal ulceration and dissection have been proposed $[18,20,21]$. Given that traumatic aneurysms can also arise from dissection, it would appear these lesions share some etiologic risk factors.

Both traumatic aneurysms and BBAs in this region are notoriously difficult to treat. Most authors agree histological classification is of limited use in determining treatment, as both have a propensity for growth and/or rupture over time without treatment $[14,21]$. Although single cases of successful treatment with primary surgical clipping have been reported, upwards of $40-60 \%$ of cases result in intraoperative rupture, as we observed [19, 22]. Thus, a variety of more definitive treatment strategies have been employed either alone or in combination, including aneurysm trapping with or without wrapping, excision or extracranial-intracranial bypass, balloon or surgical ligation of the ICA, and endovascular ICA reconstruction $[10,15,16,18]$.

Timing of intervention is also controversial, with significantly poorer outcomes for patients treated acutely when ICA sacrifice is necessary. This is likely due to additional ischemic insult from vasospasm in the setting of ICA ligation, even when adequate collateral is demonstrated angiographically [15]. Thus, some surgeons advocate operating in the chronic stage, when the aneurysm has matured and the associated vasospasm risk is diminished [23]. This must be balanced against the imminent risk of rebleeding, which is also high in these lesions. Although not the primary goal, it is likely that initial coiling of this lesion provided sufficient support to the dome of the aneurysm to allow delay in surgical treatment, such that ICA ligation did not result in a significant ischemic insult.

When acute operation is deemed necessary, high-flow bypass should be planned in the event ICA ligation is required $[10,15]$. Recent advances in endovascular stenting have provided an alternate treatment avenue, with reports of flow-diverting stent, overlapping covered stent, and coiling assisted by stent-with-a-stent technique being successfully used to treat these lesions [20, 22, 24-26]. With further experience, this may offer a less invasive, early treatment avenue for these difficult lesions.

\section{Conclusion}

Pediatric aneurysms are rare, and their etiology often differs from their adult counterparts. We report the case of a presumed traumatic pseudoaneurysm in a 15-yearold male whose location, clinical course, behavior and ultimate treatment more closely resembled a BBA. The treatment of these lesions is notoriously difficult, often necessitating open surgical trapping and/or parent vessel sacrifice with or without bypass and associated morbidity of this invasive treatment. With further advances in endovascular therapy, there is increasing potential for less invasive avenues to treat these difficult aneurysms. 


\section{References}

$>1$ Krishna H, Wani AA, Behari S, Banerji D, Chhabra DK, Jain VK: Intracranial aneurysms in patients 18 years of age or under, are they different from aneurysms in adult population? Acta Neurochir (Wien) 2005;147: 469-476.

-2 Aryan H, Giannotta S, Fukushima T, Park M, Ozgur B, Levy M: Aneurysms in children: review of 15 years experience. J Clin Neurosci 2006; 13:188-192.

3 Proust F, Toussaint P, Garniéri J, Hannequin D, Daniel Legars, Jean-Pierre Houtteville, et al: Pediatric cerebral aneurysms. 2001. ht tp://dx.doi.org.proxy1.lib.uwo. ca:2048/10.3171/jns.2001.94.5.0733.

4 Krishna H, Wani AA, Behari S, Banerji D, Chhabra DK, Jain VK: Intracranial aneurysms in patients 18 years of age or under, are they different from aneurysms in adult population? Acta Neurochir (Wien) 2005;147: 469-476.

5 Hetts SW, Narvid J, Sanai N, Lawton MT, Gupta N, Fullerton HJ, et al: Intracranial aneurysms in childhood: 27-year single-institution experience. Am J Neuroradiol 2009; 30:1315-1324.

-6 Huang J, McGirt M, Gailloud P, Tamargo R: Intracranial aneurysms in the pediatric population: case series and literature review. Surg Neurol 2005;63:424-432.

$\checkmark 7$ Vaid VK, Kumar R, Kalra SK, Mahapatra AK, Jain VK: Pediatric Intracranial Aneurysms: An Institutional Experience. Pediatr Neurosurg 2008;44:296-301

$>8$ Loevner LA, Ting TY, Hurst RW, Goldberg HI, Schut L: Spontaneous thrombosis of a basilar artery traumatic aneurysm in a child. AJNR Am J Neuroradiol 1998;19:386-388.
9 Ohba S, Kuroshima Y, Mayanagi K, Inamasu J, Saito R, Nakamura Y, et al: Traumatic aneurysm of the supraclinoid internal carotid artery-case report. Neurol Med Chir (Tokyo) 2009;49:587-589.

10 Baskaya M, Yuceer N, Egemen N: A false traumatic giant aneurysm of the supraclino. Neurol Res 1996;18:135-139.

11 Saito K, Baskaya MK, Shibuya M, Suzuki Y, Sugita K: False traumatic aneurysm of the dorsal wall of the supraclinoid internal carotid artery - case report. Neurol Med Chir (Tokyo) 1995;35:886-891.

12 Larson P, Reisner A, Morassutti D, et al: Traumatic intracranial aneurysms. Neurosurg Focus 2000;8:e4

13 Dubey A, Sung W-S, Chen Y-Y, Amato D, Mujic A, Waites P, et al: Traumatic intracranial aneurysm: a brief review. J Clin Neurosci 2008;15:609-612.

14 Ventureyra ECG, Higgins MJ: Traumatic intracranial aneurysms in childhood and adolescence. Childs Nerv Syst 1994;10:361-379.

15 Meling TR, Sorteberg A, Bakke SJ, Slettebø H, Hernesniemi J, Sorteberg W: Blood blis ter-like aneurysms of the internal carotid artery trunk causing subarachnoid hemorrhage: treatment and outcome. J Neurosurg 2008;108:662-671.

-16 Sim S, Shin Y, Cho K, Kim S, Kim S: Blood blister-like aneurysms at nonbranching sites of the internal carotid artery. J Neurosurg 2006;105:400-405.

-17 Ishikawa T, Nakamura N, Houkin K, Nomura M: Pathological consideration of a 'blisterlike' aneurysm at the superior wall of the internal carotid artery: case report. Neurosurgery 1997;40:403-405, discussion 405-406.

$>18$ Jha A, Gupta V: Blister aneurysms. Neurol India 2009;57:2
19 Ogawa A, Suzuki M, Ogasawara K: Aneurysms at nonbranching sites in the supraclinoid portion of the internal carotid artery: internal carotid artery trunk aneurysms. Neurosurgery 2000;47:578-586.

20 Kim BM, Chung EC, Park SI, Choi CS, Won YS: Treatment of blood blister-like aneurysm of the internal carotid artery with stent-assisted coil embolization followed by stentwithin-a-stent technique. J Neurosurg 2007; 107:1211-1213.

21 Regelsberger J, Matschke J, Grzyska U, Ries T, Fiehler J, Köppen J, et al: Blister-like aneurysms-a diagnostic and therapeutic challenge. Neurosurg Rev DOI: 10.1007/s10143011-0313-X.

22 Lee B-H, Kim BM, Park MS, Park SI, Chung EC, Suh SH, et al: Reconstructive endovascular treatment of ruptured blood blisterlike aneurysms of the internal carotid artery. J Neurosurg 2009;110:431-436.

23 Abe M, Tabuchi K, Yokoyama H, Uchino A: Blood blisterlike aneurysms of the internal carotid artery. J Neurosurg 1998;89:419-424.

24 Andaluz N, Zuccarello M: Blister-like aneurysms of the anterior communicating artery: a retrospective review of diagnosis and treatment in five patients. Neurosurgery 2008;62: 807-811, discussion 811.

25 Gaughen JR Jr, Hasan D, Dumont AS, Jensen ME, Mckenzie J, Evans AJ: The Efficacy of endovascular stenting in the treatment of supraclinoid internal carotid artery blister aneurysms using a stent-in-stent technique. Am J Neuroradiol 2010;31:1132-1138.

-26 Rasskazoff S, Silvaggio J, Brouwer PA, Kaufmann A, Nistor A, Iancu D: Endovascular treatment of a ruptured blood blister-like aneurysm with a flow-diverting stent. Interv Neuroradiol 2010;16:255-258. 